\title{
Palliative care for cancer patients with severe COVID-19: the challenge of uncertainty
}

\author{
Hon Wai Benjamin Cheng ${ }^{1,2}$ (1) \\ Received: 12 August 2020 / Accepted: 30 September 2020 / Published online: 1 October 2020 \\ (C) Springer-Verlag GmbH Germany, part of Springer Nature 2020
}

\begin{abstract}
Cases of coronavirus disease 2019 (COVID-19) are escalating rapidly across the globe, with the mortality risk being especially high among those with existing illness and multi-morbidity. The immunosuppressed status of some cancer patients increases their risk of infection compared with the general population, and cancer treatment within 2 weeks of COVID-19 diagnosis was reported as a risk factor for developing severe events. Palliative care workers have an essential role in the response to COVID-19 by responding rapidly and flexibly; ensuring protocols for symptom management are available, considering redeploying staffs and volunteers to provide psychosocial and bereavement care and using technology to communicate with patients and carers.
\end{abstract}

Keywords COVID-19 $\cdot$ Palliative $\cdot$ SARS $\cdot$ Cancer

\section{Introduction}

The 2019 coronavirus disease (COVID-19) is caused by severe acute respiratory syndrome (SARS) coronavirus 2 (SARS-CoV-2). The COVID-19 is primarily an acute viral respiratory disease which can manifest as acute upper or lower respiratory tract syndrome of varying severity, from asymptomatic virus shedding, rhinorrhea, sore throat, conjunctivitis to cough, asymptomatic or silent hypoxia, chest discomfort, respiratory failure, or even multi-organ failure. Extrapulmonary manifestations include diarrhea, lymphopenia, thrombocytopenia, deranged renal and liver functions, anosmia, multisystem vasculitis, and thromboembolism [1].

The outcome of COVID-19 is largely affected by older age and the presence of obesity and other underlying comorbidities [2]. Severe complications have been reported to occur in $33 \%$ of patients with COVID-19 and include acute respiratory distress syndrome, acute renal failure, acute respiratory injury,

Hon Wai Benjamin Cheng

benchw@hkstar.com

1 Medical Palliative Care Team, Department of Medicine \& Geriatrics, Tuen Mun Hospital, Tuen Mun, New Territories, Hong Kong

2 Medical Palliative Medicine (MPM) Team, Department of Medicine \& Geriatrics, R8B Rehabilitation Block, Tuen Mun Hospital, Tuen Mun, New Territories, Hong Kong SAR, China septic shock, and severe pneumonia. The crude fatality varies widely for different geographical regions from 0.4 to $10 \%$. [3]

\section{Covid-19 in cancer patients}

The immunosuppressed status of some cancer patients, whether caused by the disease itself or the treatment, increases their risk of infection compared with the general population. Cancer treatment within 14 days of COVID-19 diagnosis was reported as a risk factor for developing severe events. Acute respiratory distress syndrome (28.6\%), septic shock (3.6\%), and acute myocardial infarction (3.6\%) are among the documented severe complications in the study population [4].

Studies of the SARS outbreak in 2003 showed that interferon beta can be synergistic with ribavirin, and a combination of lopinavir-ritonavir and ribavirin can markedly improve the outcome of SARS patients in terms of mortality and respiratory failure. A recently published multicenter, prospective, open-label, randomized, phase 2 trial showed that triple antiviral therapy (interferon beta-1b, lopinavir-ritonavir, and ribavirin) was safe and superior to lopinavir-ritonavir alone in alleviating symptoms and shortening the duration of viral shedding and hospital stay in adult patients with mild to moderate COVID-19 [5]. Remdesivir was also shown to reduce time to recovery in a large randomized control [6]. Further 
research is however needed to determine their effectiveness and safety in cancer patients suffering from COVID-19.

\section{Symptoms palliation in severe COVID-19}

Symptoms can escalate rapidly among patients with severe COVID-19. A report of 6801 patients who died with COVID-19 in Italy found that the median time from symptoms onset to hospitalization was 5 days, while from symptoms onset to death was 9 days [7]. Among survivors with COVID-19, breathlessness, cough, and fatigue are the most common symptoms [8].

The mainstay of pharmacological management of severe breathlessness is opioids, with morphine being the opioid of choice in the absence of renal impairment, while fentanyl is commonly used in renal failure patients. An early case series of 101 hospitalized patients with COVID-19 who were referred to palliative care found that opioids were usually effective for palliation of breathlessness, with a median dose of $10 \mathrm{mg}$ (range 5-30 mg) subcutaneous morphine over $24 \mathrm{~h}$ [9]. While handheld fan is often used as nonpharmacological means of breathlessness control, it is not recommended in COVID-19 due to its theoretical risk of droplet spread [10]. Oxygen therapy may help relieve breathlessness in severe hypoxemic patients.

Patients with severe COVID-19 could experience anxiety and agitation due to a combination of symptoms distress, isolation, and separation from loved ones and death fears from the novel coronavirus. For people with severe agitation, especially those who may be approaching the end of life, benzodiazepines can be given either alone or in combination of strong opioids. We should acknowledge patients' fear of dying, since COVID-19 can progress rapidly, severely affecting patient's capacity in making decisions. The rapidity with which patients can deteriorate means that for many it is appropriate to have an early advance care plan in place in the event of acute deterioration [11]. This should run alongside the acute medical management plan and encompass anticipatory medication for symptoms management, as well as recognition of the patients' wishes and preferences.

Communication is also challenging for people with COVID-19 because of the uncertain outcome. Balancing hopes and fears requires both honesty and compassion. Hope-worry statements, for instance, "We are hoping for the best, but it would be wise to start planning for the worst. Knowing the full picture now, what is important to you and your loved ones at this time?", might be helpful when communicating with patients with severe COVID-19 [12]. Furthermore, emerging evidence supports use of video consultations with patients and family members as an effective and accessible method of communication [13].

\section{Conclusion}

Cases of coronavirus disease 2019 (COVID-19) are escalating rapidly across the globe, with the mortality risk being especially high among those with existing illness and multi-morbidity. The immunosuppressed status of some cancer patients increases their risk of infection compared with the general population, and cancer treatment within 2 weeks of COVID19 diagnosis was reported as a risk factor for developing severe events. The COVID-19 pandemic is still fairly new, and we need further clinical evidence on group of cancer patients at highest risk of serious complications. There is uncertainty in timing and patient selection for antiviral treatment especially for patients undergoing anticancer treatment. Furthermore, we are still striking a balance between infection control measures and good cancer care during the pandemic before vaccine is available (Table 1).

From our experience and published research, in most patients with solid and hematological malignancies, COVID-19 mortality was directly driven by older age, disease status, performance status, and by immune (e.g., neutropenia) parameters and level of inflammation (e.g., high CRP) [14].

Table 1 Uncertainties and challenges in managing cancer patients with severe COVID-19

\begin{tabular}{lc}
\hline Uncertainties & Challenges \\
\hline $\begin{array}{l}\text { - Clinical and biochemical indicators of cancer patients who are most } \\
\text { likely to develop severe COVID-19 complications remain uncertain }\end{array}$ & $\begin{array}{c}\text { - Symptoms can escalate rapidly in severe COVID-19 cancer patients, } \\
\text { especially elderly with multiple morbidities }\end{array}$ \\
$\begin{array}{l}\text { - Timing, patient selection, and choice of antivirals in COVID-19 cancer } \\
\text { patients still await further clinical evidence }\end{array}$ & $\begin{array}{c}\text { Protocols for symptoms management, including use of strong opioid and } \\
\text { advance care plan, should be made available in severely ill COVID-19 } \\
\text { patients }\end{array}$ \\
$\begin{array}{l}\text { - Efficacy and safety (including potential drug-drug interactions) of } \\
\text { anticancer treatment remain uncertain }\end{array}$ & $\begin{array}{c}\text { Consider redeploying staffs and volunteers to provide psychosocial and } \\
\text { bereavement care, under leadership of hospital palliative care team }\end{array}$ \\
$\begin{array}{l}\text { - How best to deliver cancer care, under social distancing health measures, } \\
\text { is still debatable }\end{array}$ & $\begin{array}{c}\text { - Enhance technology including telecommunications and video calls to } \\
\text { better communicate with patients and carers }\end{array}$ \\
\hline
\end{tabular}


Combination of antivirals, if considered, should be initiated before the peak of viral replication for an optimal outcome [15]. Further large-scale or multicenter studies are needed to compare the clinical features of COVID-19 disease between cancer patients and the general population and clarify whether the clearance of the virus and the recovery of COVID-19 are delayed in cancer patients.

Palliative care workers have an essential role in the response to COVID-19 by responding rapidly and flexibly; ensuring protocols for symptom management are available, considering redeploying staffs and volunteers to provide psychosocial and bereavement care and using technology to communicate with patients and carers [16, 17]. Mobile PC consultative team should be available in situation of difficult symptoms control, for instance, in cancer patients who were already receiving opioids for pain, or when goals of care being unclear in advanced cancer patients [18]. It is imperative that curative goals and success not be allowed to mask the concurrent needs for palliative care.

\section{Compliance with ethical standards}

Conflict of interest All authors have disclosed no conflicts of interest. Corresponding author has full control of all primary data and allow the journal to review the data if requested.

\section{References}

1. Chan JF, Yuan S, Kok KH et al (2020) A familial cluster of pneumonia associated with the 2019 novel coronavirus indicating person-to-person transmission: a study of a family cluster. Lancet 395:514-523

2. Zhou F, Yu T, Du R et al (2020) Clinical course and risk factors for mortality of adult inpatients with COVID-19 in Wuhan, China: a retrospective cohort study. Lancet 395:1054-1062

3. Wu Z, McGoogan JM (2020) Characteristics of and important lessons from the coronavirus disease 2019 (COVID-19) outbreak in China: summary of a report of 72314 cases from the Chinese Center for Disease Control and Prevention. JAMA. 323(13): $1239-1242$

4. Liang W, Guan W, Chen R, Wang W, Li J, Xu K, Li C, Ai Q, Lu W, Liang H, Li S, He J (2020) Cancer patients in SARS-CoV-2 infection: a nationwide analysis in China. Lancet Oncol 21(3):335337. https://doi.org/10.1016/S1470-2045(20)30096-6

5. Hung IF, Lung KC, Tso EY et al (2020) Triple combination of interferon beta- $1 \mathrm{~b}$, lopinavir-ritonavir, and ribavirin in the treatment of patients admitted to hospital with COVID-19: an open-label, randomised, phase 2 trial. Lancet 395:1695-1704

6. Beigel JH, Tomashek KM, Dodd LE et al (2020) Remdesivir for the treatment of Covid-19 - preliminary report [published online ahead of print, 2020 May 22]. N Engl J Med. https://doi.org/10.1056/ NEJMoa2007764

7. COVID-19 Surveillance Group. Characteristics of COVID-19 patients dying in Italy. Report based on available data on March 26th, 2020. https://www.epicentro.iss.it/coronavirus/bollettino/ReportCOVID-2019_26_marzo_eng.pdf. Accessed 6 Sept 2020

8. Keeley P, Buchanan D, Carolan C, Pivodic L, Tavabie S, Noble S (2020) Symptom burden and clinical profile of COVID-19 deaths: a rapid systematic review and evidence summary. BMJ Support Palliat Care:bmjspcare-2020-002368. https://doi.org/10.1136/ bmjspcare-2020-002368

9. Lovell N, Maddocks M, Etkind SN et al (2020) Characteristics, symptom management and outcomes of 101 patients with COVID-19 referred for hospital palliative care. J Pain Symptom Manag 60:e77-e81. https://doi.org/10.1016/j.jpainsymman.2020. 04.015

10. Wong SL, Leong SM, Chan CM, Kan SP, Cheng HW (2017) The effect of using an electric fan on dyspnea in Chinese patients with terminal cancer. Am J Hosp Palliat Care 34(1):42-46. https://doi. org/10.1177/1049909115615127

11. Cheng HB, Shek PK, Man CW et al (2019) Dealing with death taboo: discussion of do-not-resuscitate directives with Chinese patients with noncancer life-limiting illnesses. Am J Hosp Palliat Care 36(9):760-766. https://doi.org/10.1177/1049909119828116

12. Ting R, Edmonds P, Higginson IJ, Sleeman KE (2020) Palliative care for patients with severe covid-19. BMJ 370:m2710. Published 2020 Jul 14. https://doi.org/10.1136/bmj.m2710

13. Sutherland AE, Stickland J, Wee B (2020) Can video consultations replace face-to-face interviews? Palliative medicine and the Covid19 pandemic: rapid review. BMJ Support Palliat Care:bmjspcare2020-002326. https://doi.org/10.1136/bmjspcare-2020-002326

14. Piñana JL, Martino R, García-García I et al (2020) Risk factors and outcome of COVID-19 in patients with hematological malignancies. Exp Hematol Oncol 9:21. Published 2020 Aug 25. https://doi. org/10.1186/s40164-020-00177-Z

15. Song Y, Zhang M, Yin L, Wang K, Zhou Y, Zhou M, Lu Y (2020) COVID-19 treatment: close to a cure? A rapid review of pharmacotherapies for the novel coronavirus (SARS-CoV-2). Int $\mathrm{J}$ Antimicrob Agents 56(2):106080. https://doi.org/10.1016/j. ijantimicag.2020.106080

16. Cheng HW, Li CW, Chan KY, Sham MK (2014) The first confirmed case of human avian influenza a(H7N9) in Hong Kong and the suspension of volunteer services: impact on palliative care. $\mathrm{J}$ Pain Symptom Manag 47:e5-e7

17. Etkind SN, Bone AE, Lovell N, Cripps RL, Harding R, Higginson IJ, Sleeman KE (2020) The role and response of palliative care and hospice services in epidemics and pandemics: a rapid review to inform practice during the COVID-19 pandemic. J Pain Symptom Manag 60(1):e31-e40. https://doi.org/10.1016/j.jpainsymman. 2020.03.029

18. Quill TE, Abernethy AP (2013) Generalist plus specialist palliative care-creating a more sustainable model. N Engl J Med 368(13): 1173-1175. https://doi.org/10.1056/NEJMp1215620

Publisher's note Springer Nature remains neutral with regard to jurisdictional claims in published maps and institutional affiliations. 